\title{
Performance Analysis of Solar Photovoltaic Cells for Telecommunication Cellular Network in Remote Areas of Pakistan
}

\author{
Abdul Ghayur ${ }^{1}$ \\ Department of Electrical Engineering \\ Iqra National University \\ Peshawar Pakistan
}

\author{
Sanaullah Ahmad ${ }^{1}$ \\ Department of Electrical Engineering \\ Iqra National University \\ Peshawar Pakistan
}

\author{
Manzoor Ahmad ${ }^{1}$ \\ Department of Electrical Engineering \\ Iqra National University \\ Peshawar Pakistan
}

\begin{abstract}
In this research design and implementation of solar photo voltaic cell is done for base transceiver system (BTS) of telecom cellular networks in remote areas of Pakistan, to accomplish this task investigation is done regarding the present alternate power source of base transceiver system (BTS) that is the generator sets used as a stand-by, prime and t-prime source. This research will examine that generator sets fuel consumption and maintenance cost is considerably high and the cellular company has to pay a lot to keep a site on air and to overcome the connectivity issues.To resolve these issues this research is aimed to implement solar technology on BTS, for this purpose exploration is done regarding BTS rectifier system and suggested to use power on distribution systems 16 (PODS 16), latest technology evolution (LTE) based instead of the simple BTS rectifier, this new rectifier is intelligent and has redundant ways to overcome power issues as it has the capability to work directly on solar panel equipments and it requires DC supply. Other important factor is that solar panel recharge batteries for power backup and to keep the site on air during night time. Different cost comparison of solar and generator sets have been done by taking real data of different remote areas sites and in the end it is concluded that solar is the alternate costless, environmental friendly source of energy for BTS and can be implemented both for off-grid and on-grid systems.
\end{abstract}

Keywords-Network performance parameters, Power on distribution system, On-grid-Solar systems, Latest technology evolution

\section{INTRODUCTION}

Power sector in Pakistan is using limited and indirect sources of energy,power load shedding in telecommunication companies has considerably affected network performances and a user faces problems of connectivity, to resolve these type of connectivity issues and to keep the site on air other renewable source of energy like solar is added to the BTS site, with the addition of Power on Distribution Systems (PODS16) rectifiers. Analysis on solar and its backup batteries is done in contrast with the diesel generators on the basis of cost and maintenance problems.Different data of the Mobilink cellular company about the work plan and daily activity report of the field engineer have been carefully examined by the author and analyzed. This data contains information about North2 regions of KPK in Pakistan that contain remote sites. Currently for power generation Genset are used on BTS sites. In remote sites of BTS stand-by, prime and t-prime gensets are installed that supply power to the BTS. During non availability of utility power currently genset technology is used for running BTS system.In remote ares at least one BTS is installed in each cell which is hexagon shaped.these cells combines and form of a cluster.A cluster contains more than one BTS which is linked to a Hub site. When a Hub BTS goes down due to power issue the other linked BTS automatically goes down and the dis-connectivity issue of that area take place. This is a serious challenge for technical teams. Some of the issues due to non availability of power are given below.

- Connectivity

- Frequency reuse

- Network manageability problem

- Scalability

- Security

- Company loss and other trade offs associated with it

\section{A. Research Significance}

Telecommunication Companys competency is growing day by day. The telecommunication companies in Pakistan are looking to provide more and more services to their customers so that they can improve their market shares. So thats why they are searched for such type of operations with reduce in cost and quality of service in which they feel free and concentrate on their core business. In the current situation telecommunication companies in Pakistan are facing dis-connectivity issues in remote areas. Due to dis-connectivity issues company faces to a big loss.To avoid loss and facilitate users an alternate and direct source which is solar photo voltaic cell is an good option.

\section{B. Research Contribution}

In this research we have targeted Mobilink Company, Nokia Company Rectifiers and Solar Power One (SPO) company equipment as a case study.To examine better results we have collected data for Daily Fuel Cost, Daily Activity Report, List of Remote Sites for North-II Region from the targeted Comapnies.

The main contributions of this research are: 
- To examine the expertise of Solar Power One company.

- To examine how this Solar Photo Voltaic system is best option for Off-grid and On-grid stations.

- To prove that solar is cost effective as compared to other energy sources.

- To analyze benefits of solar relating other power sources .

- To examine remote areas BTS sites of the mobilink company

- To note BTS locations and their power status like prime, t-prime and standby.

- To investigate the benchmark,average NOC hours and load shedding time.

- To investigate about those areas where network disconnectivity issues occurs frequently.

- To examine monthly and yearly cost of fuel and maintenance.

- To point out the different ratings of gensets.

\section{BACKGROUND}

The energy that is produced by the sun rays is called solar energy.Hydrogen that has an approximate of 650000000 tons of elements is converted to Helium in seconds is the ultimate energy source from the sun, this conversion of hydrogen to helium is called as a thermonuclear process. Heat plus the electro magnetics radiations are formed during this process. Wind, Tidal, Biomass, and Hydel are the indirect incomes of the solar energy while sunlight rays that are the radiations are the direct sources of solar energy [1]. An approximate of 100000 tetra watts (TW) of solar energy reaches the earth in approximately one hour duration this much of energy is sufficient to meet the demands of the whole globe or world for one year time period it means 1 hour of $100,000 \mathrm{TW}=1$ year supply of energy for the whole world [2]. Kim a scientist said that the total 1, 62, 000 (Tera watts) of Solar energy reaches the earth but due to some factors half of it stays in the atmosphere or distributes in the atmosphere and less than half strikes the earth surface or reaches the earth apparent body [3], so it means that about 0.5 (Tera watts) of energy from the sun that is the solar radiations are used by human beings [4]. [3] done a research and he realized that other sources of energy might discharge out if they are used in tremendous amounts like coal, gas and oil, whereas the direct source of energy like wind, water, sun are renewable sources and might not be limited as they are unlimited in contrast to coal, gas and oil that are limited [5], so there is a casual that these resources might not be available after a certain amount of time period [6] or these resources might run out due to its so much use.Most of the areas in our country are directly linked with solar radiations as sunlight or sun shines for about 2000-3500 hours per annum. A total of 2.0 to 3.1 Megawatts hour per meter square per year or MW h $/ \mathrm{m}^{2} /$ year that is equivalent to $6.7 \mathrm{KW} / \mathrm{h} / \mathrm{m}^{2}$ day of the power [7] capability. Pakistan has an ultimate climate to take advantage of the solar radiations. Our province Baluchistan that has the largest square feet area is measured to be area having the peak solar energy rays or radiations. Baluchistan province of Pakistan is supplemented with the maximum solar light radiations. $20-21 \mathrm{MJ} / \mathrm{m}^{2} /$ day [8] is the Baluchistan daily solar radiations figure, these values may vary slightly with little difference and are ideal for solar panels and solar appliances. The average sun shine in Pakistan is 8 to 9 hours [9] which is best for solar panels to give a good output.

\section{Methodology}

This research is composed of quantitative analysis which contain cost analysis for fuel consumption of gensets, cost analysis for replacing solar system, power calculation required for BTS, solar panel power generation and batteries play back period. Data was collected using face to face interviews and by questionnaires. the range of employees for data collection was upto 300 from all companies.

\section{A. Population}

Currently below mentioned company are working in Pakistan which are providing their services in the field of wired/wireless communication and broad bands.

Wired/wireless companies in Pakistan

- Mobilink

- PTCL

- Naya Tel

- World Call

- Telenor

- NTC

- Ufone

- Warid

- Zong

Companies in the field of equipment manufacturer and transporter.

- Power One

- Schneider

- Nokia rectifiers

\section{B. Sample and Sample Size}

The targeted company for our research is Mobilink and the region was North-II region. Due to easily accessibility of data and regional office of Mobilink company we kept it as a sample. Analysis on solar is achieved by the help of the staff of solar company private limited, and the key points of analysis include.

- Finding the load of Solar Panels

- Finding the total energy for solar

- Finding Solar Panel size, based on the number of time/ hours of Sunlight 
- $\quad$ Finding Battery size

- $\quad$ Finding the size of Solar Charge Controller

- $\quad$ Finding Inverter Size

Solar panels can be easily deployed both in on and off-grid systems. Batteries provide backup to the system and depends on the use of the sytem the time required to run the batteries actually if we increase the size of the batteries than backup time is exteneded and also if we increase the amount of solar panels than we also have more power source to charge the batteries quickly for longer use , actually more solar panels are required for areas where there is less sunlight than normal daylight conditions, also for remote areas where there is no supply of electricity such as Bajaur, Dir, Dikhan,Bannu these are areas where there is less or no electricity supply, such areas are better for solar installation to decrease costs and maintenace problems of sites .Site will be always on air and there will be no connectivity issue as continous power is available to BTS. There are usually two types of batteries

- Lead acid batteries that are rechargeable batteries with different potential differences.

- Dry batteries that are also rechargeable and include lithium, alkaline and silver oxide batteries

The payback period of solar is not more than five years

\section{Diesel Generator sets}

Normally a diesel generator working load varies from 5 KVA to $500 \mathrm{KVA}$, also we know that for an ideal case power factor is 1 , than if we assume that power factor is 0.8 than we can easily convert real power or active power to apparent power by formula. $\backslash \mathrm{KVA}=\frac{K W}{\text { Power Factor }}$, so for 8 $\mathrm{KW}$ we have $\mathrm{KVA}=\frac{8}{0.8}=10$ apparent power also if the load increases oil intake of generators also increases. To calculate the units consumed in 1 hour than 1 x $8 \mathrm{KW}=8 \mathrm{KWH}$. 1 liter of diesel is equivalent to $0.84 \mathrm{KG}$ or $0.8 \mathrm{KG}$ round than, if a diesel consumes $10 \mathrm{KGs}$ of oil than it is equivalent to $\frac{10}{0.84}=11.90$ Liter.

\section{Data collection}

To analyze final results we have collected data by using questionnaires and direct interviews. interviews was collected at regional offices of KPK which is place in Peshawar region. To get explained and cleared interviews we have observed about 300 of employees from all companies in very relax mode. Quantitative data was from fresh data base records and receipts. duration of interviews with one person was upto 20 minutes. Targeted companies was expertises in installation of solar panel and their power feed back.

\section{E. Interview Responses}

Response of employee was in good,relax mode and understandable. some of the questions which was asked during interviews are mentioned below.

Q1) What is the payback period of these solar power systems installed by SPT? Answer: Although the initial cost of these systems is high but it is one time investment and all the systems are exempt from the monthly or yearly bills. Hence, the money that is invested on these systems can be returned back within few months or years depending upon the type of system being installed. Beside this, there is no maintenance cost and for each system; the company also offers the warrantee. The cost analysis has been done to find out payback period of each system mathematically.

Q2: Do you think solar energy technology is the best option in the present energy situation of Pakistan? If yes, can you justify your answer? Answer: Yes indeed, solar energy is the best alternative technology that can be used in the present energy situation of Pakistan. There are many factors that strongly support the implementation of solar energy in Pakistan. These are as follows:

- Pakistan is ranked at position 6th throughout the world for receiving high solar radiations.[14]

- In most part of the country, the sun shines for an average of 3000 hours/year.

- The provinces of Punjab, Sindh and Baluchistan receives approximately $2500 \mathrm{KWh}$ of solar radiation per square meter for one year, while Khyber Pakhtun khwa receives approximately $2200 \mathrm{KWh}$ of solar radiation per square meter for one year[15].

- 7000 mega joules of solar energy are being wasted every year, which can be otherwise efficiently utilized in order to minimize the energy shortfall.

Q3: Share your views about the promotion of these solar technologies in Pakistan over the recent years? Answer: These improvements are as follows:

- Availability of a wide range of solar products.

- $\quad$ Prices of solar products have declined from 2009 onwards, due to expansion in its sales market.

- Conventional tube wells are upgraded to solar energy that saves a lot of power to the national grid.

- Water heather have also been upgraded to solar system which is also a source to save energy.

Q4: As a sales manager of the Solar Power Traders what are the main needs of the people? Answer: The needs of people are mainly regarding the solar home off grid systems, solar water pumps and the solar water heaters.

\section{F. Method of Analysis}

Remote areas BTS gensets data was gathered from Mobilink employees, cluster and site engineers the data contains remote areas NORTH2 region activity report and daily activity plan in Microsoft excel, fuel cost was calculated for different sites in NORTH2, also a simulation was implemented using a schematic BTS load, Grid, PV(2KW,3KW), GENSETS(8KVA,12KVA), Converter and Batteries in Homer pro micro grid analysis tool. PODS 16 rectifiers usage and its deployment with alternate energy sources like solar was carefully analyzed to get the results.

IV. ANALYSIS 
TABLE I. SOLAR AND GENSETS MAINTENANCE COSTS FOR ONE MONTH

\begin{tabular}{|c|c|c|}
\hline No. of Days & Solar \& Genset Maintenance Cost \\
\hline S.no & Solar & Gensets \\
\hline 1 & 0 & 1000 \\
\hline 3 & 0 & 15000 \\
\hline 5 & 0 & 10000 \\
\hline 7 & 0 & 2000 \\
\hline 9 & 1000 & 9000 \\
\hline 12 & 0 & 15000 \\
\hline 15 & 0 & 900 \\
\hline 18 & 0 & 500 \\
\hline 24 & 0 & 500 \\
\hline 30 & 15000 & 20000 \\
\hline
\end{tabular}

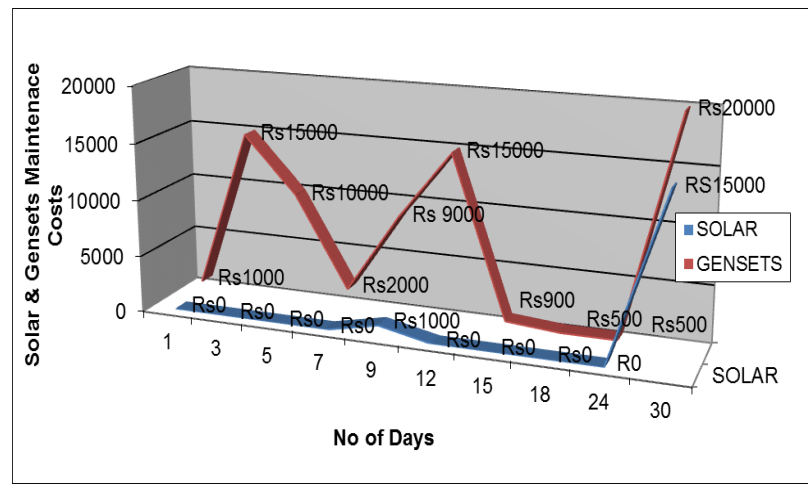

Fig. 1. Solar and Gensets maintenance cost

\section{FUEL COSTS COMPARISONS FOR GENSETS}

As we know that the updated price of diesel is Rupees. 83.79 , so for taking a remote area BTS site of DI-KHAN 1,848 liters of diesel is consumed in 55 hours duration as the benchmark of diesel generator for this site is 1.4 liters per hour so Rupees $1,54,844$ is spent, on the other side in solar no fuel cost is needed as solar panel takes power from direct sunlight. The simulation results of solar and gensets is also shown in the figure.

\begin{tabular}{|c|c|}
\hline DIESEL GENSET FUEL COSTS FOR THREE DAYS \\
\hline FUEL & COST \\
\hline Liters 1848 & Rs $1,54,844$ \\
\hline
\end{tabular}

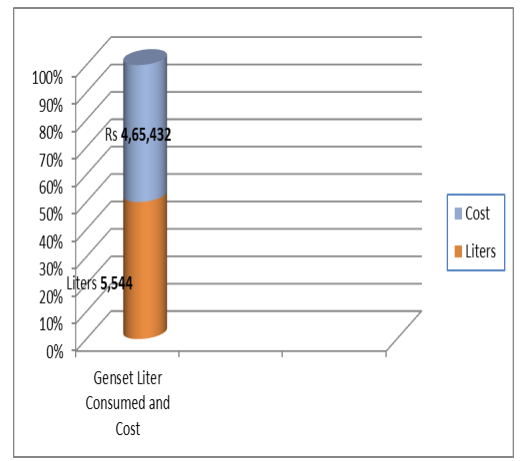

Fig. 2. Diesel gensets fuel costs for three days

For DI-KHAN site genset operating for ten days will cost round about Rupees 4,65,432 and fuel consumed in liters is 5,544 , whereas on the other hand solar is free of cost on the basis of fuel, also a simulation is also carried out in the homer pro.

\begin{tabular}{|c|c|}
\hline \multicolumn{2}{|c|}{ DIESEL GENSET FUEL COSTS FOR TEN DAYS } \\
\hline FUEL & COST \\
\hline Liters 5544 & Rs 4,65,432 \\
\hline
\end{tabular}

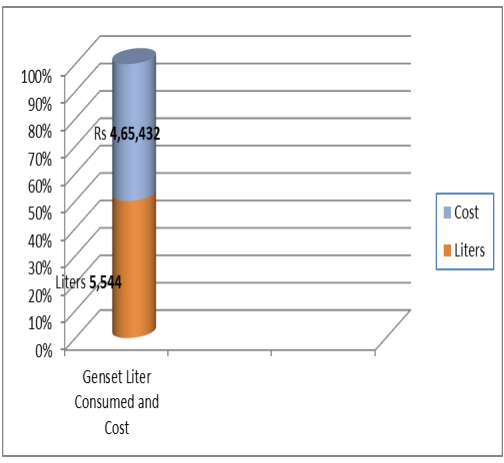

Fig. 3. Diesel gensets fuel costs for ten days

For DI-KHAN site genset operating for 30 days, or one month will cost round about Rupees 13,93,596 and fuel consumed in liters is 16,632 , whereas on the other hand solar is free of cost on the basis of fuel.

\begin{tabular}{|c|c|}
\hline DIESEL GENSET FUEL COSTS FOR THIRTY DAYS \\
\hline FUEL & COST \\
\hline Liters 16,632 & Rs $13,93,596$ \\
\hline
\end{tabular}

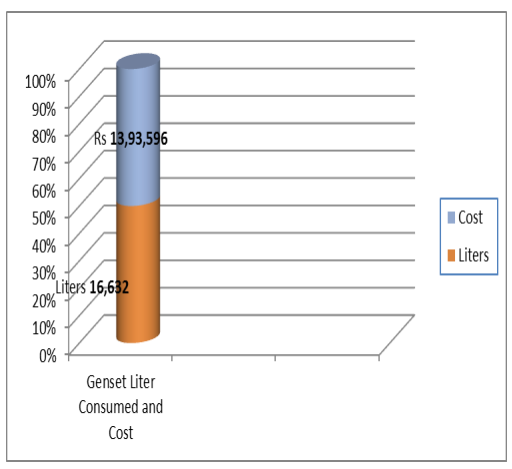

Fig. 4. Diesel gensets fuel costs for thirty days

For DI-KHAN site genset operating for 365 days, or one year will cost round about Rupees 1,67,23,143 and fuel consumed in liters is $1,99,584$, whereas on the other hand solar is free of cost on the basis of fuel.

\begin{tabular}{|c|c|}
\hline DIESEL GENSET FUEL COSTS FOR ONE YEAR \\
\hline FUEL & COST \\
\hline Liters $1,99,584$ & Rs $1,67,23,143$ \\
\hline
\end{tabular}




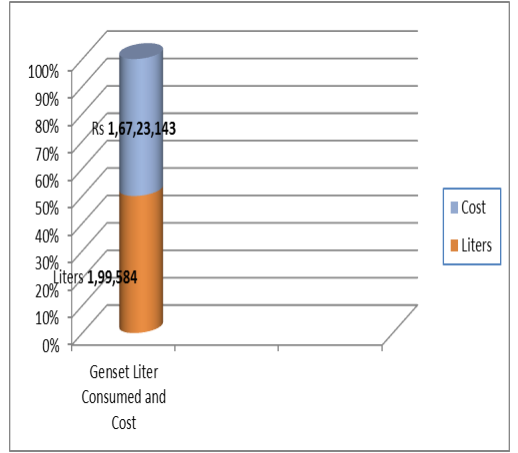

Fig. 5. Diesel gensets fuel costs for one year

\section{A. Sensitivity Analysis}

You can use many inputs in order to find different variations in results using a powerful tool homer. These multi input variables are called the sensitivity variables. These sensitivity variables are likely to help the user to cover different inputs on a system and help to find out uncertainty in a system. These sensitivity variables are used for hourly, and monthly data sets of electric load.

\section{B. Hybrid Power Analysis}

Different power sources ,hydro, wind energy and solar can be easily deployed to a system and its net effect on the system can be easily derived from it on the basis of cost and other performance parameters.

\section{Optimization Analysis of Power Gensets and Comparison with Solar}

Model analysis on the basis of different possible results are achieved using homer as a simulation tool, by varying the number of batteries, solar, size of converter, costs and other decision variables.

\section{Scaling Process}

Scaling process is necessary to find out the total magnitude of the load data with an option that dosent changes the daily load.

\section{HOMER SIMULATION RESULTS}

The results of homer simulation are as follow.

\section{TABLE II. HOMER SIMULATION RESULTS OF DI-KHAN SITE}

\begin{tabular}{|c|c|}
\hline Project Location \\
\hline Location & DI-Khan Pakistan \\
\hline Latitude & 66 Degrees 34.24 minutes north \\
\hline Longitude & 19 Degrees 57.07 minutes west \\
\hline Time Zone & Etc/GMT \\
\hline
\end{tabular}

This graph shows us per kilo watt hour use of gensets used for DI-Khan area, the calculation used depicts homer simulation results for 10KVA and 20KVA per one day usage.
TABLE III. LOAD ANALYSIS

\begin{tabular}{|c|c|}
\hline Load \\
\hline Data source & Synthetic \\
\hline Daily noise & $10 \%$ \\
\hline Hourly noise & $20 \%$ \\
\hline Scaled annual average & $24,000.000 \mathrm{KWh} / \mathrm{d}$ \\
\hline Scaled peak load & $1,833.2300 \mathrm{KW}$ \\
\hline Load factor & 0.5455 \\
\hline
\end{tabular}

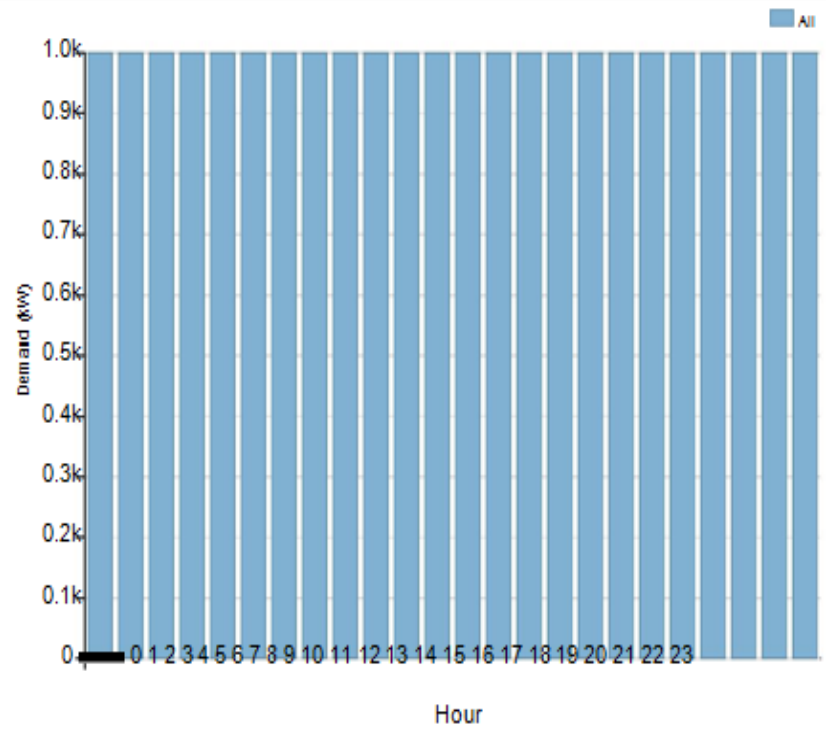

Fig. 6. Diesel gensets per kilo watthour demand

TABLE IV. Photovoltaic CELls Size AND Cost

\begin{tabular}{|c|c|c|c|}
\hline \hline PV Generic Flat plate PV & \multicolumn{3}{|c|}{} \\
\hline Size & Capital & Replacement & O\&M \\
\hline $2 K W$ & Rs300,0000 & Rs30,000 & Rs18,900 \\
\hline $3 K W$ & Rs410,000 & Rs42,000 & Rs30,240 \\
\hline
\end{tabular}

TABLE V. SOLAR SPECIFICATION IN HOMER USED FOR ANALYSIS

\begin{tabular}{|c|c|}
\hline Solar Resource \\
\hline Sizes to consider & $2 \& 3 \mathrm{KW}$ \\
\hline Scaled annual average & $5.14 \mathrm{kWh} / \mathrm{m}^{2} / d$ \\
\hline Lifetime & 25 year \\
\hline Derating factor & $80 \%$ \\
\hline Tracking system & Horizontal axis, monthly adjustment \\
\hline Slope & $66.571 \mathrm{deg}$ \\
\hline Azimuth & $0.651 \mathrm{deg}$ \\
\hline Ground reflectance & $20.0 \%$ \\
\hline
\end{tabular}

TABLE VI. GENSETS SPECIFICATION ANALYSIS USED IN HOMER SIMULATION

\begin{tabular}{|c|c|}
\hline \multicolumn{2}{|c|}{ Generator:10KVA\&20KVA } \\
\hline Sizes to consider & $12 \& 15$ \\
\hline Scaled annual average & 15,000 hours \\
\hline Lifetime & $15,000 \mathrm{hrs}$ \\
\hline Min load ratio & $25 \%$ \\
\hline Heat recovery ratio & $39 \%$ \\
\hline Fuel used & Diesel \\
\hline Fuel curve intercept & $0.0480 \mathrm{~L} / \mathrm{hr} / \mathrm{kW}$ \\
\hline Fuel curve slope & $0.2860 \mathrm{~L} / \mathrm{hr} / \mathrm{kW}$ \\
\hline Diesel cost per liter & $\mathrm{Rs} 83.40 / \mathrm{L}$ \\
\hline Lower heat value & $43.2 \mathrm{MJ} / \mathrm{Kg} / \mathrm{m}^{3}$ \\
\hline Carbon content & $88.0 \%$ \\
\hline Sulfur Content & $0.3 \%$ \\
\hline
\end{tabular}




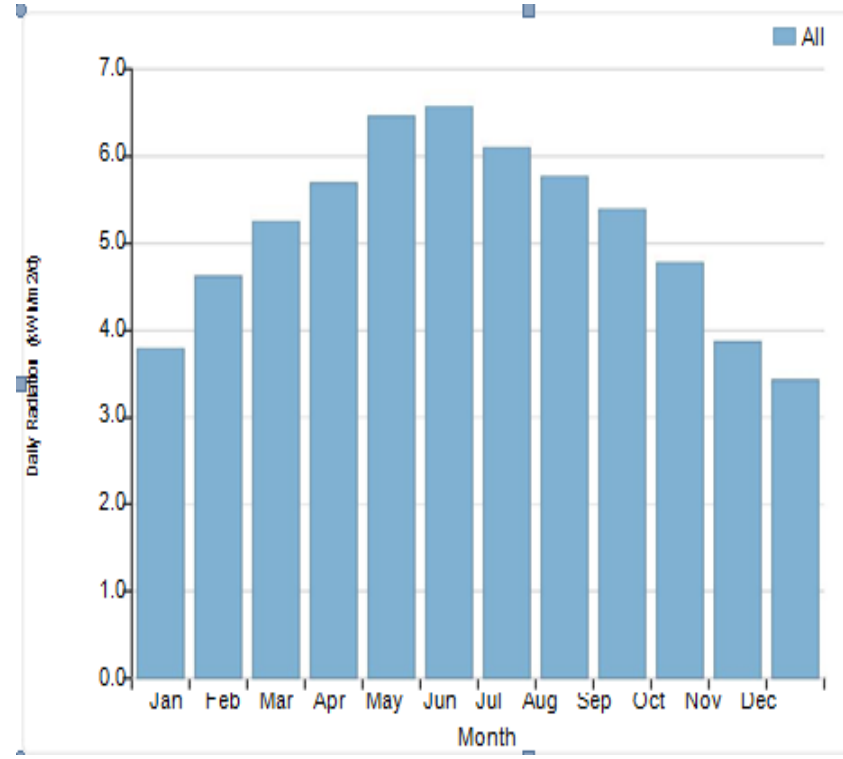

Fig. 7. Solar usage and performance

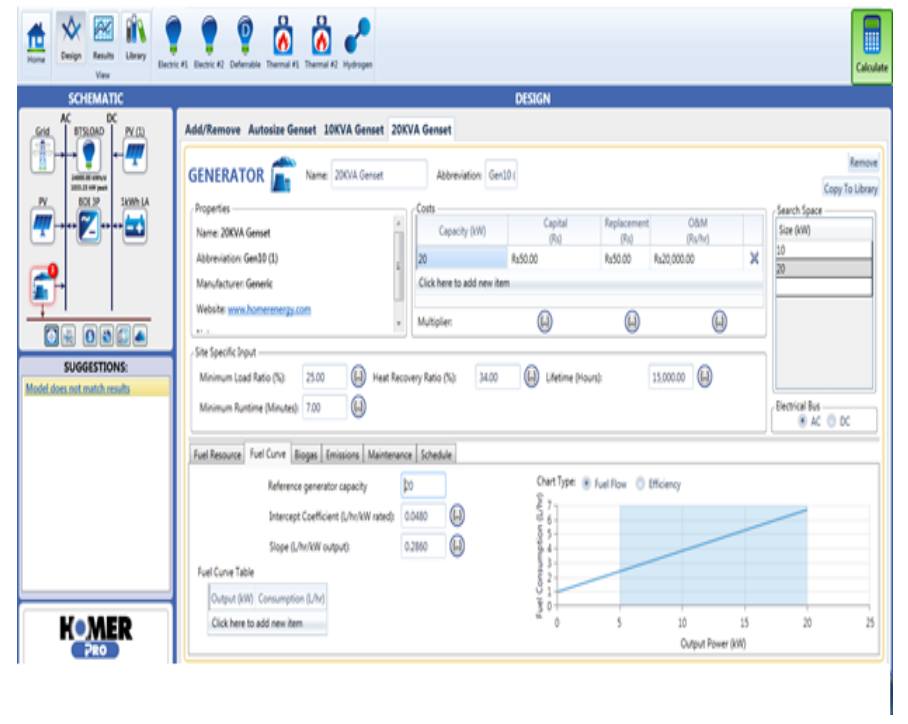

Fig. 8. Diesel gensets fuel costs and scaled usage results

\begin{tabular}{|c|c|}
\hline \multicolumn{2}{|l|}{ Battery(1kwh lead acid) } \\
\hline Quantities to consider & 320,550 \\
\hline Voltage & $12 \mathrm{~V}$ \\
\hline Nominal capacity & $83 \mathrm{Ah}$ \\
\hline Lifetime throughput & {$[800] \mathrm{kWh}$} \\
\hline
\end{tabular}

\begin{tabular}{|c|c|}
\hline \multicolumn{2}{|c|}{ Converter } \\
\hline Quantities to consider & $125,0 \mathrm{~kW}$ \\
\hline Lifetime & $10 \mathrm{yr}$ \\
\hline Inverter can parralel with AC generator & YES \\
\hline Lifetime throughput & {$[800] \mathrm{kWh}$} \\
\hline
\end{tabular}

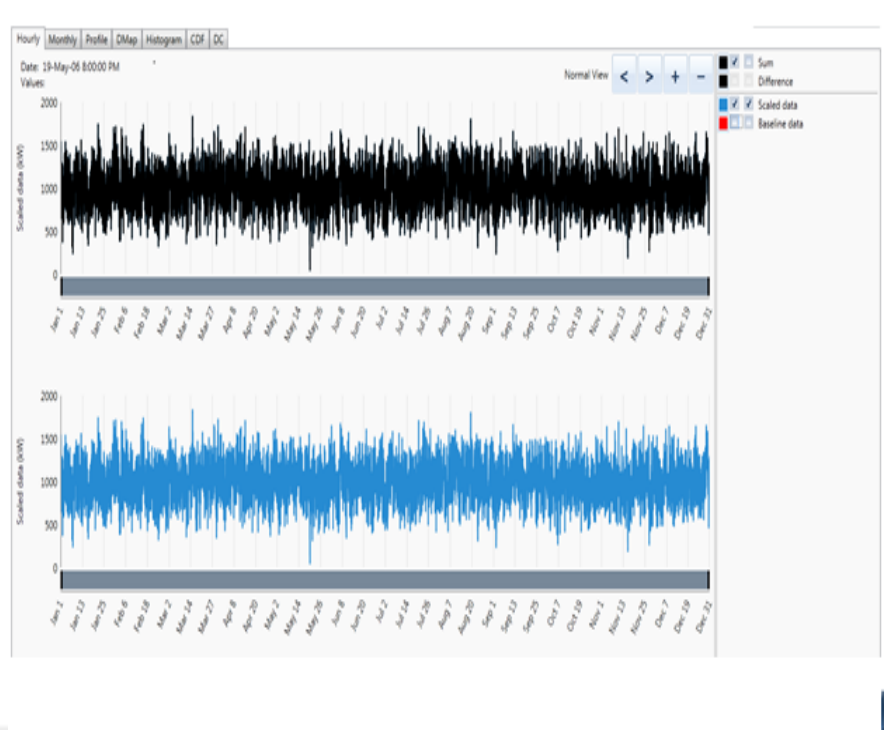

Fig. 9. comparison of solar and gensets during BTS load(site on air)

TABLE VII. OVERALL HOMER SIMULATION SYSTEM CONTROL TABLE

\begin{tabular}{|c|c|}
\hline \multicolumn{2}{|c|}{ System Control } \\
\hline Check load following & YES \\
\hline Check cycle charging & YES \\
\hline Setpoint state of charge & 80 \\
\hline Allow system with multiple generators & YES \\
\hline Allow multiple PV cells to operate simultaneously & YES \\
\hline Allow system with generator capacity less than the peak load & YES \\
\hline Maximum annual capacity shortage & 80 \\
\hline Minimum renewable fraction & 8 \\
\hline Operating reserve as percentage of hourly load & 20 \\
\hline Operating reserve as percentage of solar power output & 85 \\
\hline Operating reserve as percentage of peak load & 30 \\
\hline
\end{tabular}

\section{RESULTS}

On the basis of the above comparisons I prefer solar to be installed on BTS and replace genset as it is costly because of its fuel consumption and maintenance. Apart from cost genset is harmful for environment as its smoke contains chemicals harmful for environment and on the other side solar is environmental friendly. Other important factor is that taking fuel to remote areas is quite difficult and maintenance team became exhausted as it has to take fuel to remote areas of our country.

\section{CONCLUSION}

On behalf of the total data gathered and to the point meaning of that is that comparisons results of both solar and gensets have been studied, cost of solar and gensets have been compared, total data gathered from Mobilink north2 region sites have been categorized on the basis of activity plan and activity report. Rough assessment of solar and its installation on behalf of the new LTE equipment of power that is the power on distribution (PODS) 16 rectifier have been discussed to show that solar can take t-prime or use T-prime for BTS instead of the gensets as it is costly especially for remote areas sites of the mobilink company. 


\section{FUTURE WORK}

This research can further be extended by adding all areas of Pakistan such as North-I, Center-I, Center-II. Telecommunication sector in Pakistan is divided into these four regions in which we have worked out for only North-II region Remote areas. We examine cost and performance analysis for solar photo voltaic system vs. gensets for targeted region.so the future work area of this research is directed to analyze for remaining three regions.

\section{REFERENCES}

[1] Brown, Eric. William. (1988). An introduction to solar energy. College of Computer and Information Science. Feneric. Published

[2] Abdul Waheed bhutto, Aqeel Ahmad Bazmi, and Gholamreza Zahedi, 2011. Greener energy: Issues and challenges for PakistanSolar energy prospective. Renewable and Sustainable Energy Reviews. Published

[3] title=Realization of a near-perfect antireflection coating for silicon solar energy utilization, author=Kuo, Mei-Ling and Poxson, David J and Kim, Yong Sung and Mont, Frank W and Kim, Jong Kyu and Schubert, E Fred and Lin, Shawn-Yu, journal $=$ Optics letters, volume $=33$, number $=21$, pages $=2527-2529$, year $=2008$, publisher $=$ Optical Society of America. Published

[4] Sealite, The benefits of solar power, s.l.: s.n. in press

[5] Harry Husted, 2010. Solar energy and its use today. published

[6] Zulfiqar Ali,July 2013. KP people find solace in solar energy, Peshawar: DAWN.com. Anon., 2010. [Online] Available at: http://www.valopia.com/index.php/pdf/Solar/solar-energy-advantagesbenefits-a-disadvantages.pdf .Published

[7] Mark Sauders, 2015. Research Methods for business students. Harlow: Pearson. Book

[8] Syed Turab Hussain, 2014. Pakistans Energy Sector Issues: Energy Efficiency and Energy. The Lahore Journal of Economics. Published

[9] Hassan Nawab,30th Jan 2013. Energy situation in Pakistan, Islamabad: s.n.

[10] SUNTECH, 2013. SUNTECH COLLABORATES WITH AEDB TO DELIVER SOLAR TO PAKISTAN, Beijing: s.n. Traders, S. P., 2013. For a bright and clean future. [Online] Available at: http://www.solarpower.com.pk/aboutus.php [Accessed 22 july 2013]. Website

[11] Lawrence Neuman James, 2015. Social Research Methods. Boston: Pearson Education, Inc. Book

[12] Umar Khan Mirza, Maroto-Valer, Mercedes Maroto-Valer. and Nasir Ahmad, 2003. Status and outlook of solar energy use. Elsevier. Published

[13] title=Critical success factors for successful lean Six Sigma implementation in Pakistan, author=Zhang, Qun and Irfan, Muhammad and Khattak, $M$ and Abbas, Jaffar and Xiaoning, $Z$ and Shah, $M$, journal=Interdisciplinary Journal of Contemporary Research In Business, volume $=4$, number $=1$, pages $=p 117-124$, year $=2012$. Published

[14] Qazi Nauman, Zahid, 2015. MARKET ENTRY MODE FOR SOLAR AND WIND ENERGY BASED ON MARKET ANALYSIS FOR PROSPECTIVE FINNISH COMPANIES, Published

[15] Nadeem, Mukhtar, Hayat, and Rafique, 2015. Power sector- An overview 